\title{
Uma reflexão sobre o ensino aprendizagem de ecologia em aulas práticas e a construção de sociedades sustentáveis.
}

Ana Maria de Andrade Caldeira

\section{Resumo}

Neste trabalho apresentamos uma revisão sobre o conceito de ecologia e como este evoluiu ao longo de sua história. E procuramos realizar uma reflexão sobre o processo de ensino aprendizagem de ecologia, utilizando como recurso didático aulas práticas em ambientes naturais. Buscamos relacionar a compreensão dos conceitos ecológicos com a formação cidadão do aluno. Pois acreditamos que através do ensino aprendizagem de ecologia podemos capacitar os alunos a possivelmente levar em consideração os conceitos ecológicos em suas atividades sociais. O que talvez possibilitaria sua participação na construção da almejada sociedade sustentável.

Palavras-chave: ecologia, ensino aprendizagem de ecologia, aulas práticas, meio ambiente, desenvolvimento sustentável.

\begin{abstract}
In this work we present a revision on the ecology concept and as this evolved throughout its history. E we look for to carry through a reflexion on the ecology learning and education process, being used as didactic resource practical lessons in natural environments. We search to relate the understanding of the ecological concepts with the formation citizen of the pupil. Therefore we believe that through education ecology learning we can enable the pupils to possibly take in consideration the ecological concepts in its social activities. What perhaps it would make possible its participation in the construction of the longed for sustainable society.
\end{abstract}

Keywords : ecology, ecology learning and education, practical lessons, environment, sustainable development. 


\section{Introdução}

A ecologia é a ciência que estuda a relação entre os seres vivos e seu meio nas seguintes escalas: Temporal, ou seja, como os organismos se comportam diante das variações periódicas de seu meio.Espacial, ou seja, qual a influencia da localização espacial na distribuição dos organismos e biológica. Esta última pode ser estudada nos seguintes níveis hierárquicos: Organismo, as adaptações individuais dos organismos ao meio e a seu modo de vida. População, a forma como os indivíduos de uma mesma espécie se desenvolvem nas populações. Comunidade, como ocorrem as complexas inter-relações entre os indivíduos de diversas espécies nas comunidades. Ecossistema, como as diversas comunidades se inter-relacionam com o meio circundante e finalmente em um nível hierárquico global a biosfera, ou seja, como ocorrem fenômenos de abrangência global como por exemplo as correntes marítimas, a migração de animais, o aquecimento global e o el niño e la niña. É importante destacar que as divisões expostas são conceituais e didáticas, pois na realidade, para o estudo ecológico todas as escalas e níveis hierárquicos são considerados, e o desenvolvimento dos ecossistemas ocorre de maneira integrada (Ricklefs, 2003).

No ensino médio a ecologia é tratada como um dos conteúdos curriculares da disciplina biologia. Por tratar-se do estudo das inter-relações dos seres vivos com o meio apresenta-se como um componente curricular potencialmente interdisciplinar. $\mathrm{O}$ objeto de estudo da ecologia, na escala biológica, dá-se em diversos níveis hierárquicos. Portanto para resolver seus problemas conceituais (e práticos) necessitamos de, praticamente, todos os conteúdos da disciplina biologia. Dentre eles: citologia, anatomia, fisiologia, biodiversidade, genética e evolução (Linhares e Gewadsznajder, 2005). Dessa forma a ecologia pode funcionar como um excelente tema gerador para o ensino aprendizagem da disciplina biologia.

A iniciativa deste trabalho surgiu com o propósito de realizar uma reflexão e fomentar o debate sobre o processo de ensino e aprendizagem de ecologia. Para tanto, no presente artigo, buscamos expor alguns dos conceitos aceitos pela comunidade cientifica sobre a ciência ecologia e como esta se consolidou como ciência desde o final do século 18 e como vem sendo desenvolvida nos dias atuais.

Acreditamos que a possibilidade de apresentação de fenômenos próximos a realidade do aluno é de extrema relevância para o processo de ensino e aprendizagem de ecologia. Uma forma de realizar a apresentação de fenômenos naturais é utilizando, como recurso didático, aulas de campo em ambientes naturais, principalmente aqueles que encontrados espacialmente próximos aos alunos por sua facilidade e pela possibilidade dos alunos possuírem experiência prévia com o ambiente objeto de estudo. As aulas práticas de ecologia em ambientes naturais podem ser um ótimo recurso didático tanto por seu aspecto estético motivador e por proporcionar a experiência 
do fenômeno natural integro, ou seja, como ele ocorre na realidade (Seniciato, 2006), além disso a aula prática quando utilizada no processo de ensino aprendizagem de ciências oferece, segundo Caldeira (2005), uma riqueza de possibilidades para o processo de construção do conhecimento cientifico.

Para Mucci (2005) o homem por ser dotado de juízo tem a capacidade de alterar o meio em que vive de forma a torná-lo adequado a sua sobrevivência. Porém notamos nos dias atuais que esta capacidade de alteração ambiental tem produzido uma séria crise ambiental. Este problema afeta toda a humanidade, causando redução na qualidade de vida global. Tal crise tem se agravado nas últimas décadas em decorrência do estilo de vida consumista e dos modos de produção da sociedade industrial. Tudo isso tem chamado a atenção dos ambientalistas, e gerado um contraponto que foi discutido em diversos fóruns mundiais, como por exemplo nas conferencias de Estocolmo (1972) e Rio-92 (1992), e esta em pauta inclusive nos dias atuais, este contraponto é o desenvolvimento sustentável. Tal conceito de desenvolvimento leva em consideração os custos ecológicos da manutenção de nossa sociedade, e propõe a busca de novas formas de organização social, de produção e também de paradigmas. Acreditamos que os conceitos ecológicos, por buscar compreender o funcionamento complexo da natureza e seus processos ecológicos, é fundamental na construção de uma sociedade nova e sustentável. Portanto procuramos relacionar a importância do ensino de ecologia com a formação de indivíduos capazes de realizar a construção dessa almejada sociedade sustentável.

\section{Ecologia enquanto ciência}

Tomemos um exemplo citado por Raven et al. (2001, p. 741):

"[...] quando vemos uma flor num jardim ou uma arvore num parque, não imaginamos a multiplicidade de meios pelos quais o crescimento da planta é influenciado por uma diversidade de organismos como bactérias, fungos, pequenos $e$ grandes animais e outras plantas. As plantas são afetadas não apenas pelas conhecidas condições ambientais, como luz solar, precipitação pluviométrica, mas também por fatores sutis, como $\mathrm{pH}$ do solo e níveis de macro nutrientes e micronutrientes. Para complicar ainda mais o assunto, os organismos no ambiente onde se encontram podem exercer sua influencia diretamente por interagir com componentes inertes de modo a afetar o crescimento da planta. Por exemplo, bactérias podem alterar o $\mathrm{pH}$ do solo, que por seu turno influencia o vegetal". 
A etimologia da palavra ecologia tem origem no grego "oikos", que significa casa, e dessa forma, pode-se dizer que a ecologia é o estudo da circunvizinhança imediata dos organismos vivos, seria o estudo da casa, ou de forma mais genérica, do lugar onde se vive.

É um fato banal obsevar que muitas vezes pratica-se ecologia sem saber. Por exemplo o pescador sabe que as tainhas devem ser capturadas nas regiões dos rios com maior correntesa com aguás bem oxigenadas, ao passo que os "peixes brancos" como o bagre encontram-se nas regiões lentas dos rios. Ou mesmo, que é mais facil capturar robalos próximos a margem do estuário, um dos locais onde buscam alimento, pois estes encontram-se "abobados" pela falta de oxigênio nas águas dessa região.

Segundo Dajoz (1983) o conhecimento empirico das exigencias ecológicas dos seres vivos podia ser notado já no homem pré histórico, que o tinha adiquirido durante a caça e coleta de vegetais comestiveis, assim como na busca de abrigos e refúgios com um microclima favorável, além disso, no pensamento de numerosos sábios da antiguidade e da idáde média podemos encontrar elementos ecológicos.

Dajoz (1983) se propoz a realizar uma breve revisão histórica do surgimento da ecologia, para tanto, realizou uma revisão dos autores que considera importantes na história do surgimento dessa ciência, o que pode ser encontrado a seguir.

As idéias de Malthus (1798) em sua obra, An essay on teh principle of population, indicam que enquanto os indivíduos multiplicam-se em progresão geométrica os recurssos alimentares crescem somente em progressão aritimética, tiveram profunda influencia sobre a noção de "luta pela vida", proposta por Darwin (1859) em sua obra teórica On the origin of species, que assegurou o triunfo do transformismo. Darwin (1881) foi um dos pioneiros da ecologia principalmente em sua pesquisa sobre minhocas, The formation of vegetable mould.

Forbes (1843), em seus estudos sobre a distribuição dos animais no Mar Egeu observa que as diversas zonas de profundidade contêm espécies caracteristicas, o que põe em evidência o caráter dinâmico das inter-relações organismos-meio. A partir de 1850 Hunboldt, Candolle, Engler e Gray fundam a geografia botânica. Mobius (1877), estudando bancos de ostras, introduz o termo biocenose 1 . O suiço Forel (1892) funda, com seu estudo no Lago Léman, a liminologia. Murray e Hjort (1912) estabelecem em bases sólidas a oceanografia.

${ }^{1}$ Grupo de seres vivos reunidos pela atração não recíproca exercida sobre eles pelos diversos fatores do meio; este grupamento caracteriza-se por determinada composição em espécies, pela existência de fenômenos de interdependência e ocupa um espaço chamado biótopo (Dajoz, 1983, p. 277). 
Até aproximadamente 1930 acumulam-se os trabalhos estudando as reações dos animais aos diversos fatores do meio, dentre estes podemos destacar os autores anglo saxões Shelford (1913), Adams (1913), Davenport (1903) e Chapman (1931). Uvarov (1931) desenvolve em suas pesquisas os conceitos relativos a influência dos fatores físicos do meio sobre o comportamento de insetos.

A dinâmica de populações da seus primeiros passos com os trabalhos matemáticos, sobretudo teóricos de, Volterra (1926), Gause (1935) e Lotka (1934). Várias controvésias levantadas na França nessa mesma época conduziram Prenant (1934) a realizar uma revisão dos conceitos ecológicos, publicada sob o titulo de Adaptation, écologie et biocénotique. Ao mesmo tempo que se multiplicam os estudos de ecologia surgem as primeiras aplicações agricolas e florestais, ainda pouco numerosas.

Fundam-se sociedades, Bristish Ecological Society (1913), Ecological Society of America (1916), assim como periódicos especializados: Journal of ecology (1913), Ecology (1920), Ecological monographs (1931) e Journal of animal ecology (1932).

Pinto-Coelho (2000), Ricklefs (2003) e Begon et al. $(2006,2007)$ realizaram uma revisão dos conceitos e definições desta ciência presentes no pensamento de diversos cientistas, o que pode ser encontrado a seguir.

Foi em 1869 que o cientista alemão Ernst Haeckel, quem pela primeira vez, usou o termo ecologia, em sua obra Generelle Morphologie der Organismen, para designar o estudo ciêntifico das relações entre os seres vivos e o ambiente em que vivem.

Por ecologia, queremos dizer o corpo de conhecimento referente à economia da natureza - a investigação das relações totais dos animais tanto com seu ambiente orgânico quanto com seu ambiente inorgânico; incluindo, acima de tudo, suas relações amigaveis ou não amigáveis com aqueles animais e plantas com os quais vêm direta ou indiretamente entrar em contato - numa palavra , ecologia é o estudo de todas as inter-relações complexas denominadas por Darwin como as condições da luta pela existência. (Haeckel, 1969 apud Ricklefs, 2003 p. 2).

Burdon-Sanderson (1893) defende uma definição muito próxima a esta, quando define a ecologia como ciência que busca compreender as relações externas de plantas e animais entre si e com as condições passadas e presentes de suas existencias.

Tansley (1904) defende que o campo de estudo da ecologia são as relações entre as plantas e o meio ambiente . Já Elton (1927) define a Ecologia como história natural cientifica e como a ciência principalmente relacionada com o que pode ser chamado de sociologia e economia de animais, e não com a estrutura e outras adaptações que eles representam. 
Andrewartha (1961) define Ecologia como o estudo cientifico da distribuição e da abundancia de organismos. Odum (1988) define esta ciência como biologia de grupos de organismos e o estudo da estrutura e da função da natureza. Esta é uma definição que ressalta a relevância dos processos eco fisiológicos na determinação da estrutura dos ecossistemas.

Para Krebs (1972) a Ecologia trata-se do estudo cientifico das interações que determinam a distribuição e a abundancia dos organismos. Tal definição segundo Pinto-Coelho (2000) trata-se de uma visão que busca ressaltar a importância das interações bióticas (competição, predação) na estruturação das comunidades. Para Begon et al. (2007) a definição de Krebs localiza o tema central da ecologia: onde os organismos ocorrem, quantos ocorrem em um determinado loca e por quê.

Para Ricklefs (2003) é o estudo do meio ambiente enfocando as inter-relações entre os organismos e seu meio circundante. Pode-se observar que esta definição invoca noções físicobiológicas.

Begon et al. (2007, p.1) propõe uma definição da ecologia como "o estudo cientifico da distribuição e abundância dos organismos e das interações que determinam a distribuição e a abundância".

A Ecologia, segundo Raven et al. (2001) pode ser basicamente enunciada no estudo dos ecossistemas. Ecossistema designa o conjunto formado por todos os fatores bióticos e abióticos que atuam simultaneamente sobre determinada região. Considerando como fatores bióticos as diversas populações de animais, plantas, fungos e microoganismos e os abióticos os fatores físicos, como a água, o sol, o solo, o gelo e vento.

Odum (1988) define ecossistema como um conjunto de fatores bióticos (componente autotrófica, que é capaz de fixar energia luminosa e produzir alimento a partir de substâncias inorgânicas; componente heterotrófica, que utiliza, rearranja e decompõe os materiais complexos sintetizados pela componente autotrófica) e abióticos (elementos básicos e compostos do meio; fatores ausentes da presença de seres vivos, como temperatura, luz, água, entre outros), em que ocorre uma interação entre os organismos vivos e o ambiente físico, com a formação de um fluxo de energia e uma ciclagem de materiais entre as partes viva e não viva.

Em sua revisão Seniciato (2006) conclui que a ecologia assume o objetivo de investigar e compreender as relações que os seres vivos mantém entre si e com o ambiente.

Ainda segundo Seniciato (2006, p. 4):

"A Ecologia surge então como a ciência que se propõe a estudar as complexas relações envolvidas na existencia de todos os seres vivos, o que inclui, obviamente, o homem e o poder de suas ações sobre a natureza." 
Concluimos que a ecologia apresenta-se como uma ciência essencialmente sistêmica, que busca entender as complexas relações entre seres vivos e entre estes e seu meio.

"Genericamente, sistemas complexos são aqueles compostos de muitos elementos e/ou subsistemas diferentes interagindo espacialmente e temporalmente de forma não linear, gerando padrões emergentes que são observáveis apenas em escalas maiores." (Souza; Buckeridge, 2004, p. 409).

Segundo Ricklefs $(2003)$ e Begon et al. $(2006,2007)$ a ecologia atua em escalas temporais, espaciais e biológicas. A hierarquia biológica começa com partículas subcelulares e continua com células, tecidos e órgãos. A ecologia ocupa-se dos níveis seguintes, no nível de organismo busca saber como os indivíduos são afetados e afetam o ambiente, no nível de população procura a presença/ausência e abundancia/raridade de espécies determinadas, a ecologia de comunidades trata da estrutura de comunidades ecológicas. Num nível de ecossistema, onde temos a interação das comunidades com o meio físico, é incluído a transformação e o fluxo de energia e matéria. Para Begon et al. (2006, p. 28) "As transformações de energia e matéria estão subordinadas as interações".

Segundo Ricklefs (2003) podemos focalizar no extremo espectro de sistemas ecológicos a biosfera, nesse nível analisamos os movimentos de massas de ar, água, e da energia e os elementos químicos que eles contêm e que definem o clima e a distribuição de espécies e a produtividade dos ecossistemas.

È também nesse nível em que a Ecologia busca compreender as variações naturais no clima, como o El Niño, e as variações provocadas por ações antrópicas, como o buraco na camada de ozônio e o aquecimento global. Embora cada abordagem se relacione a um nível diferente de hierarquia dos sistemas ecológicos, eles são retratados num único plano de indagação cientifica, com cada abordagem interagindo com as outras em graus variados (Ricklefs, 2003).

Assim o objeto de estudo da ecologia pode dar-se em diversos níveis hierárquicos, desde o mais particular até o mais abrangente. Tal como a relação entre uma determinada espécie de protozoário com uma determinada espécie de inseto, de determinada espécie de inseto com determinada espécie de planta, até um nível mais abrangente, como é o caso das relações que envolvem a estrutura e o funcionamento, de comunidades vegetais e animais, e do ciclo da matéria e fluxo de energia dentro dos ecossistemas (Seniciato, 2006).

Por meio da ecologia podemos compreender as características emergentes e a dinâmica interna dos sistemas complexos expressos na teia de relações entre seus diversos componentes, vivos e não vivos. 
Nesse tipo de sistema complexo, muitos elementos interagindo produzem caracteristicas especificas. A alteração de um único elemento pode causar modificações em todo o sistema, acarretando a evidencia de caracteristicas emergentes, que podem modificar consequentemente toda a estrutura e funcionamento do sistema.

No caso dos ecossistemas naturais a eliminação ou extinção de individuos que desempenham papéis fundamentais no ecossistema pode acarretar uma perda posterior de diversidade e diminuição da resiliência ${ }^{1}$ do ecossistema como um todo, desbalanceando os ciclos biogeoquimicos (Philippi Jr. e Malheiros, 2005). Mesmo a alteração de uma propriedade física do ecossistema pode causar um grande prejuizo para as espécies que ali se desenvolvem. Para Queiroz e El-Hani (2005, p. 29) propriedades emergentes podem ser entendidas em sentido técnico como "...uma certa classe de propriedades de um nível superior que se relacionam de uma certa maneira com a micro-estrutura de uma classe de sistemas".

Por exemplo na biosfera uma alteração das propriedades de um ecossitema local podem promover consequências. Tomemos alguns exemplos: A liberação de dióxido de carbono, proveniente de ações antrópicas ou naturais, acabou causando uma mudança no comportamento de toda a atmosfera, isto se refletiu em uma mudança na estrutura de todo o ecossistema global (Assunção e Malheiros, 2005). Segundo Begon et al. (2006) essas mudanças provavelmente resultarão no derretimento das calotas polares e como consequência o aumento do nivel dos mares e trazendo grandes alterações no padrão climático global e na distribuição de espécies. Pode-se esperar que essas alterações influenciem os padrões mundiais de distribuição dos bolsões de fome e doenças.

Segundo Ricklefs (2003), os ecólogos empregam em seus estudos as três facetas da investigação cientifica, a observação e a descrição, o desenvolvimento de hipóteses ou explicações e, finalmente, o teste dessas hipóteses, frequentemente com experimentos. 0 mesmo autor $(2003$, p. 14) apresenta exemplos que demonstram o papel proeminente da percepção no desenvolvimento do conhecimento ecológico:

"[...] a exploração durante o século 19 estabeleceu que o número de especies animais $e$ vegetais nas regiões tropicais excedia grandemente o das regiões temperadas. $O$ reconhecimento desta relação entre biodiversidade e latitude surgiu de comparações de observações acumuladas de muitos cientistas até que se confirmassem como um padrão geral.".

\footnotetext{
${ }^{1}$ A capacidade de um ecossistema se recuperar, depois de cessadas as perturbações que o levaram
} a atingir um determinado nível de degradação (KAZMIERCZAK, 1998). 
A hipótese é uma idéia de como o sistema funciona, e pode ajudar o pesquisador a compreender um certo padrão observado para então realizar previsões sobre seu comportamento. Numa etapa seguinte podemos desejar compreender como, ou mesmo por que, esse padrão funciona, dirigindo assim nosso olhar perquiridor para um nível hierarquico superior ou inferior. Se queremos nos convencer de que uma hipótese é válida, nós a colocamos em teste, somente de vez em quando uma idéia pode ser provada sem sombra de duvida, mas quanto mais exploramos as implicações de nossa hipótese através de previsões e observações, verificamos que ela é consistente ou caso mesmo uma falácia (Ricklefs, 2003).

Begon et al. (2006) destaca que o avanço seria impossivel se os estudos ecológicos fossem limitados apenas aos ambientes naturais. E mesmo em ambientes naturais, manipulações experimentais são aplicadas na busca de evidencias seguras. Segundo Ricklefs (2003) as hipóteses fortes podem ser testadas experimentalmente, em que o pesquisador, controla uma ou mais variáveis. Tais hipóteses podem, também. ser testadas num microcosmo, uma estrutura que tenta reproduzir as caracteristicas essenciais de um sistema ecológico em um laborátório ou montagem de campo simplificado. E, muitas vezes, os ecólogos utilizam a modelagem matemática onde o pesquisador busca elaborar um conjunto de equações que representem o sistema complexo. Esses recursos metodológicos segundo Begon et al. (2006), têm desempenhado papel decisivo no desenvolvimento da ecologia.

Por outro lado segundo Mucci (2005), os ecossistemas são complexos, sua dinâmica depende de inúmeras variáveis. Portanto, seu funcionamento não deveria ser reduzido apenas a equações matemáticas, que quando resolvidas produzem modelos gerais que muitas vezes desconsideram as particularidades de cada individuo e de suas diversas interações.

Para Begon et al. (2007) a modelagem matemática é fundamental na ecologia, principalmente no que tange as previsões, porém é no mundo real que são aplicados tais modelos, e o valor destes em termos de elucidações sobre o funcionamento dos sistemas naturais.

Os passos da compreensão ecológica passam pela observação dos fenômenos naturais, formulação de hipóteses e em alguns casos modelizações. A ecologia apesar de utilizar como ferramenta para seu desenvolvimento diversas representações da realidade não pode prescindir desta em nenhum momento. Pois é o objetivo dessa ciência segundo Begon et al. (2006) com a ajuda da compreensão dos fenômenos naturais poder prever, manejar e controlar o comportamento dos ecossistemas.

$\mathrm{Na}$ ecologia os modelos gerais servem como uma referencia para a pratica desta ciencia, ou mesmo para a previsão de certos fenomenos. Porem é na realidade que a ecologia se desenvolve e pode ser aplicada. Apenas através da experiencia é que podemos respeitar as 
individualidades de cada organismo, de cada população, de cada comunidade e de cada ecossistema, confrontando os modelos gerais com as particularidades, e elaborando assim novos conceitos que determinarão nossa conduta futura.

Como uma ciência dessa natureza poderia ser ensinada de maneira plena utilizando apenas representações prontas, leis gerais que não são colocadas em conflito com seu próprio objeto de estudo?

\section{Aulas práticas em ecossistemas naturais e o ensino aprendizagem de ecologia}

Como destaca Pinheiro (2007) o ensino de ecologia baseado unicamente em aulas teóricas no ambiente escolar é deficiente, porém ainda é muito comum nas escolas. A utilização de aulas de campo não é uma estratégia de ensino comum na grade curricular do ensino médio, talvez por exigir tanto do professor quanto do aluno certa disposição e compromisso.

Lopes e Allain (2002) destacam em sua pesquisa que, a quantidade maior de fenômenos quando comparada a uma aula tradicional, pode confundir os alunos na construção dos conceitos e para lidar com essa complexidade é necessário o estabelecimento de objetivos claros e um professor bem preparado.

Segundo Santos (2002), as da aula de campo de Ciências e Biologia em um ambiente natural podem ser positivas na aprendizagem dos conceitos à medida que são um estímulo para os professores, que vêem uma possibilidade de inovação para seus trabalhos e assim empenhamse mais na orientação dos alunos. Cavassan e Seniciato (2004) acreditam que para os alunos é importante que o professor conheça bem o ambiente a ser visitado e que este ambiente seja limitado, no sentido espacial e físico, de forma a atender os objetivos da aula.

Na sala de aula onde lidamos com representações ecológicas prontas e acabadas, muitas vezes "roubamos" do aluno os importantes passos de vivência da realidade estudada, onde irão ocorrer as impressões estéticas motivadoras da conduta e aprendizado, e a elaborações de hipóteses (característica fundamental do pensamento cientifico) sobre o fenômeno observado.

Como afirma Caldeira $(2005$, p. 7) sobre o ensino de ciências :

"[...] o ensino de ciências não deve fundamentar-se na memorização de conteúdos distantes da realidade dos alunos, mas precisa permitir ao aluno a elaboração de sua própria interpretação. Mais do que ensinar ciências é preciso possibilitar o raciocinar sobre e através dos fenômenos naturais." 
Ao apresentarmos o meio ambiente ao corpo discente durante as práticas de campo permitimos aos alunos elaborar sua própria interpretação a partir de uma realidade próxima. Os significantes vão sendo elaborados sobre e através dos fenômenos naturais.

O uso de aulas de campo em ambientes naturais tem sido freqüentemente recomendado por oferecer oportunidades de contato direto com o ambiente natural, direcionado ao aprendizado e à sensibilização. Além disso, como afirmam Curado e Angelini (2006, p. 396), as aulas práticas "proporcionam oportunidades de reflexão sobre valores, indispensáveis a mudanças comportamentais que estejam em equilibrio com a conservação dos recursos naturais."

Nesse sentido, a interpretação em áreas naturais, segundo Robim e Tabanez (1993), é uma estratégia educativa que integra o ser humano com a natureza, motivando-o a contribuir para a preservação dos ambientes naturais.

Robim e Tabanez (1993) apontam, ainda, que enquanto na educação formal o aluno tem uma repetição de ambiente com presença obrigatória diária, a visita a locais informais proporciona estímulos à curiosidade e ao interesse, que por sua vez facilitam o processamento de formações e o aprendizado.

Ainda, segundo os construtivistas, dentre eles Piaget (2001), o conhecimento é construído pelo sujeito cognoscente. Em termos amplos, Piaget postulou a existência de esquemas cognitivos que são formados e se desenvolvem por meio da coordenação e da internalização das ações de um indivíduo sobre os objetos do mundo. Esses esquemas se desenvolvem como resultado de um processo de adaptação a experiências mais complexas (através do processo que Piaget denominou equilibração). Com isso se afirma que a criança só aprende e compreende efetivamente se ela puder explorar o seu meio, envolvendo-se ativamente na construção do seu próprio conhecimento.

Não é nossa intenção neste trabalho condenar o processo de ensino que utiliza representações, pois é bem possível a construção de conceitos efetivos nesse ambiente educacional, inclusive no desenvolvimento desta pesquisa recursos como documentos oficiais, livros didáticos, imagens, giz e lousa foram fundamentais. Segundo Santaella (1983, p. 10) “...também nos comunicamos e nos orientamos através de imagens, gráficos, sinais, setas, números, luzes... Através de objetos, sons musicais, gestos, expressões, cheiro e tato, através do olhar, do sentir e do apalpar".

Possibilitando um maior numero de abordagens sobre o objeto, potencializamos o processo de reconstrução do conhecimento uma vez que toda forma de representação é de certa forma parcial. Assim a apresentação do objeto dinâmico é também essencial uma vez que esta apresentação pode favorecer a percepção que é sempre carregada em primeiridade, e onde o 
objeto é mostrado com sua riqueza de detalhes e com todos os elementos perceptíveis. Potencializando a capacidade do aluno em formular questões, hipóteses explicativas e leis gerais.

Ao utilizarmos apenas representações prontas e acabadas nunca vamos alcançar o mesmo valor estético, e toda a potencialidade de compreensão do fenômeno frente à experiência colateral. A representação é muito limitada: o signo não pode fazer conhecer nem reconhecer o objeto: apenas o representa, diz algo sobre ele. $O$ signo assim indica o objeto dinâmico. $O$ intérprete o descobre por "experiência colateral".

Como aponta Caldeira (2005, p. 169):

"Apresentar fenômenos primariamente amplia as possibilidades de interpretações, desde que novas linguagens possam ser engendradas no percurso do apresentar-relacionar-reapresentar. A experiência colateral só pode ser adquirida se vivenciada de maneira mais variada possivel, principalmente em se tratando de ensino de conceitos biológicos."

A metodologia de percepção/estabelecimento de relações/conceituação proposta por Caldeira (2005) é interessante nesse sentido, não podemos prescindir da percepção no processo de ensino aprendizagem, assim como não é possível para o ecólogo prescindir da realidade ambiental e trabalhar apenas com modelos teórico, uma vez que, o objetivo da ecologia, como afirmou Begon et al. (2006), é com a ajuda da compreensão dos fenômenos naturais poder prever, manejar e controlar o comportamento dos ecossistemas.

As etapas estabelecidas para esse percurso gerativo de interpretantes são descritas de acordo com Caldeira (2005, p. 74):

"O pesquisador, observador, parte de percepções sincréticas sensoriais que the despertam o Objeto de análise sem estabelecer vínculos com os possíveis conflitos com o real. A seguir, em contato com o real e com os conflitos gerados por ele, busca, nas percepções indiciais, elementos que Ihe permita relacionar os dados 'difusos' obtidos na etapa posterior aos elementos agora engendrados a fim de perquirir as possiveis alternativas para resolvê-los. Por fim e ao cabo, elabora hipóteses abertas para desvelar o Objeto pesquisado tendo em mente alcançar um interpretante formal que Ihe garanta uma possível explicação a qual será retomada em pesquisas posteriores."

Além disso a experiência colateral, a percepção são envolvidas pela motivação, e esta se relaciona com os aspectos emotivos, estético motivadores presentes nas aulas de campo, como apontam os resultados de Seniciato (2006): As aulas de campo proporcionam maior motivação e 
envolvimento emocional dos alunos, ao mesmo tempo em que favorecem o entendimento sobre os ambientes naturais e a construção do conhecimento cientifico.

A aula de campo em ambientes naturais é mais eficaz que aulas teóricas segundo Seniciato $(2006$, p. 5)

"[...] aulas de campo nos próprios ambientes naturais são mais eficazes, em comparação às aulas teóricas, no alcance desses objetivos por proporcionarem tanto uma visão mais integrada dos fenômenos, quanto um maior envolvimento emocional com o assunto, acarretando no aumento do conhecimento."

As aulas de Ciências e Biologia desenvolvidas em ambientes naturais além de envolverem e motivarem crianças e jovens constituem, ainda, um instrumento de superação da fragmentação do conhecimento (Seniciato, 2006).

De certa forma ao sentir a motivação estética o individuo é compelido à interpretação de certo fenômeno, o que acaba facilitando o processo de reconstrução do conhecimento cientifico. Segundo Heemann (2003, p. 113):

"As percepções originadas das vivencias com a natureza despertam sentimentos estéticos e valorativos nem sempre definíveis. Da mesma forma presentes na música, no teatro, na arte em geral, tais sentimentos também participam da formulação dos princípios éticos e da gênese das teorias cientificas."

Portanto a apresentação dos ambientes naturais é fundamental para um aprendizado significativo dos conceitos ecológicos. Tanto pelo seu valor estético motivador do aprendizado, como pela riqueza em fenômenos ocorrendo de maneira integrada.

Nas aulas práticas de campo, ou seja, na apresentação do fenômeno estudado (objeto dinâmico), oferecemos a possibilidade da interpretação signica do objeto dinâmico através de uma experiência colateral, desse modo às potencialidades de geração de significantes é plena (em relação à mente interpretante). Em contraposição as aulas teóricas que lidam com representações (textos, mapas, fotos, diagramas, etc.), ou seja, com objetos imediatos do signo, oferecem apenas uma visão parcial dos ecossistemas estudados, e uma menor potencialidade de formação de significantes.

O conhecimento determina nossa conduta, portanto o conhecimento do funcionamento dos ecossistemas deve ser a base de qualquer ação social, uma vez que atualmente enfrentamos sérios problemas ambientais que podem por em risco a saúde e qualidade de vida da humanidade. E qualquer ação de manejo sustentável dos recursos naturais deve ter como principio os conceitos ecológicos, para que seja garantida a qualidade de vida e o direito a uma ambiente saudável para esta e as próximas gerações, como assegurado na constituição de 1988. 
Portanto para a formação do cidadão a compreensão da Ecologia é fundamental, uma vez que como afirmou Ricklefs (2003) o conhecimento dos processos ecológicos é a resposta para a criação de sociedades sustentáveis.

\section{0 conceito de Meio Ambiente}

Segundo Milaré (2001), a expressão meio ambiente foi utilizada pela primeira vez pelo naturalista francês Geoffroy de Saint-Hilaire (1835) em sua obra Études progressives d'un naturaliste, e foi perfilhada por Augusto Conte em seu Curso de Filosofia Positiva.

A Lei 6.938/81, Lei da Política Nacional do Meio Ambiente, define o que se entende por meio ambiente como: "o conjunto de condições, leis influencias e interações de ordem física, química e biológica, que permite, abriga e rege a vida em todas as suas formas (grifo nosso)".

Milaré (2001, p. 63), acredita que a expressão meio ambiente não é redundante, e explica:

"Tanto a palavra meio como o vocábulo ambiente passam por condições diferentes, quer na linguagem cientifica quer na vulgar. Nenhum desses termos é unívoco (detentor de significado único), mas ambos são equívocos (mesma palavra com significados diferentes). Meio pode significar aritmeticamente, a metade de um inteiro; dado contexto físico ou social; um recurso ou um insumo para se alcançar ou produzir algo. Já ambiente pode representar um espaço geográfico ou social, físico ou psicológico, natural ou artificial (grifo nosso). Não chega, pois, a ser redundante a expressão meio ambiente, embora no sentido vulgar a palavra ambiente indique $o$ lugar, o sítio, o recinto, o espaço que envolve os seres vivos e as coisas."

Em um sentido técnico Nebel (1990), define meio ambiente como uma combinação de todas as coisas e fatores externos ao individuo ou população de indivíduos em questão. Milaré (2001), argumenta que podemos distinguir duas visões da expressão meio ambiente:

A visão estrita, que considera o meio ambiente nada mais que o patrimônio natural, e as relações com e entre os seres vivos, desprezando tudo aquilo que não diga respeito aos recursos naturais.

A visão ampla, que considera que o meio ambiente abrange toda a natureza original (natural) e artificial, assim como os bens culturais correlatos. 
- Meio ambiente natural, constituído pelo solo, pela água, pelo ar, pela energia, pela fauna e pela flora.

- Meio ambiente artificial, ou humano, formado pelas edificações, equipamentos e alterações produzidos pelo homem no meio ambiente natural.

Assim devemos considerar que nem todos os ecossistemas são naturais. Silva (2000, p.2), defende esta visão ampla do meio ambiente e o conceitua como "a interação do conjunto de elementos naturais, artificiais e culturais que propiciem o desenvolvimento equilibrado da vida em todas as suas formas".

Coimbra (1985) compartilha a mesma concepção quando expõe que meio ambiente:

"[...] é o conjunto dos elementos físico-químicos, ecossistemas naturais e sociais em que se insere o homem, individual e socialmente, num processo de interação que atenda ao desenvolvimento das atividades humanas, á preservação dos recursos naturais e das características essenciais do entorno, dentro de padrões de qualidade definidos."

Segundo Milaré (2001), estes conceitos, de meio ambiente, são mais facilmente intuíveis que definíveis, em virtude da riqueza e complexidade do que encerra, representado o que chamou de noção "camaleão", pois não se encontra um acordo entre os especialistas sobre o que seja meio ambiente, suas definições exprimem, queiramos ou não, as paixões, expectativas e incompreensões daqueles que dela cuidam.

\section{Ensino de ecologia e a realidade sócio-ambiental.}

O ensino de Ecologia pode ser considerado fundamental na formação do aluno, não apenas na acepção de conhecedor dos conteúdos e processos científicos, mas também, e principalmente, enquanto cidadão. Machado (1982) afirma que só cuidamos, respeitamos e preservamos aquilo que conhecemos e que a ignorância traz uma visão distorcida da realidade. Isso porque o estudo da Ecologia trás para a realidade do aluno, um ser humano, muitas vezes no início de sua formação, uma série de hábitos e processos cognitivos que serão utilizados por toda a sua vida, em várias áreas que não a Ecologia em si. O estímulo a constante a formulação de questões, a pesquisa em busca de respostas, a percepção de que das opções feitas hoje em relação ao meio ambiente depende o futuro da espécie humana, que nossas atitudes são determinantes e que temos responsabilidade em relação à manutenção das condições de vida / 
homeostase do planeta, são de extrema importância na construção de um ser humano com melhores hábitos.

Segundo Mucci (2005) o Homo sapiens sapiens por ser dotado de juízo, raciocínio e poder de abstração tem a capacidade de modificar o meio em que se encontra de modo a torná-lo adequado a sua sobrevivência. Ainda segundo o autor o Homo sapiens tem no seu surgimento, a alguns milhões de anos durante o pleistoceno, o marco da degradação ambiental e pode ser considerado o maior poluidor de todos os seres vivos.

Para Fink (2005), o ser humano é ser animal inserido no contexto de todos os ecossistemas ambientais, e por sua natureza racional, é o único de por em risco a vida no planeta ou é o único a salva-la de si próprio.

Souza (2000, p.86), apresenta uma definição de ecologia, com elementos sociais, muito interessante, a seguir:

"Ecologia é a ciência que estuda as relações entre o sistema social, o produtivo e o de valores que lhe serve de legitimação, características da sociedade industrial de massas, bem como o elenco de conseqüências que este sistema gera para se manter, usando o estoque de recursos naturais finitos, dele se valendo para lograr seu objetivo econômico. O campo de ação da ecologia é o estudo das distorções geradas na natureza pela ação social deste sistema; seu objetivo maior é identificar as causas, no sentido de colaborar com as políticas no encaminhamento das soluções possiveis à nossa época."

Segundo Milaré (2001), esta visão se apropria melhor a ecologia social do que à ecologia como biociências, porém acredita que a superação de limites disciplinares que se entrevê nessa definição é altamente elucidativa e provocante. Para o autor apesar de tal visão causar estranheza,pois foge as definições mais ortodoxas e apela para contribuição de outras ciências, apresenta conteúdo bastante objetivo e ao mesmo tempo abrangente no que concerne as atuais relações planetárias, e supera a visão haeckeliana, de um século e meio atrás, para pensar numa ecologia holística em que as relações são perturbadas pela espécie humana em detrimento da homeostase de toda a biosfera.

Desta maneira, a educação em ecologia, além de se orientar pelos paradigmas didáticos vigentes e tradicionais deve assumir sua responsabilidade na construção de um novo homem, com hábitos de conduta condizentes com o almejado desenvolvimento sustentável, podendo planejar novos modelos integrados de desenvolvimento que não causem o desbalanceamento dos fluxos de energia dos ciclos de matéria nos diversos ecossistemas naturais e antrópicos (Philippi Jr. e Malheiros, 2005) O conceito de sociedade sustentável pode ser definido de maneira simples e clara como sendo uma sociedade que satisfaz suas necessidades sem diminuir as 
perspectivas das gerações futuras. Segundo Begon et al. (2006), uma atividade sustentável é aquela que pode ser continuada ou reproduzida em um futuro previsível.

Segundo Philippi Jr. e Malheiros (2005, p. 59) a constituição brasileira de 1988 no que se refere à inserção do conceito de desenvolvimento sustentável em seu texto:

"Todos têm direito ao meio ambiente ecologicamente equilibrado, bem de uso comum do povo e essencial à sadia qualidade de vida, impondo-se ao poder público e à coletividade o dever de defendê-lo e preservá-lo para as presentes e futuras gerações."

Este é o maior desafio de nosso tempo, criar comunidades sustentáveis, ou seja, ambientes sociais e culturais onde podemos satisfazes nossas necessidades e aspirações sem diminuir as chances das gerações futuras.

Para Ricklefs (2003, p. 2), o manejo de recursos naturais numa forma que sustente uma razoável qualidade de vida humana "depende do uso inteligente dos princípios ecológicos para resolver ou prevenir problemas ambientais, e para suprir o nosso pensamento e praticas econômicas políticas e sociais."

Begon et al. (2006) destaca que a preocupação em criar uma sociedade sustentável surge porque grande parte das atividades humanas são nitidamente insustentáveis. O autor (2006, p.442), exemplifica estas atividades:

"A população humana global não poderá continuar aumentando de tamanho; não poderemos continuar a retirar peixe do mar mais rápido que a capacidade de repor os cardumes perdidos (se quisermos ter peixe para comer no futuro); não podemos continuar a explorar culturas agrícolas em florestas se a qualidade e quantidade do solo se deteriora e os recursos hídricos se tornam inadequados; não poderemos continuar a usar os mesmos pesticidas se os números crescentes de pragas se tornarem resistentes a eles; não poderemos manter a diversidade da natureza se continuarmos a provocar a extinção de espécies."

Os conceitos ecológicos são fundamentais na elaboração de uma sociedade sustentável e é nosso dever enquanto educadores desenvolver esses conceitos de maneira fecunda e efetiva. Deve ser nossa preocupação enquanto professores, auxiliar os alunos na aquisição e consolidação de um conjunto de conhecimentos, que devem sim ter como referencial os conceitos essenciais desta Ciência, mas devemos procurar ir além desses conceitos. Portanto uma formação que capacite os alunos, a participação na tomada de decisões e elaboração de políticas públicas que conservem os processos ecológicos responsáveis por sua produtividade, é uma formação que 
inclui os conceitos ecológicos. Isto porque os processos ecológicos contêm a chave para a política ambiental (RICKLEFS, 2003).

Segundo Philippi Jr. e Malheiros (2005, p. 64), o entendimento das diferenças ecológicas entre os diversos ecossistemas, naturais e antrópicos, é importante no processo educacional "para que a sociedade compreenda o impacto de suas ações no meio ambiente, e, portanto, o resultado dessas modificações no aumento do risco de agravo à saúde pública e à qualidade de vida."

Segundo Mucci (2005, p. 36)"...a solução dos problemas ambientais passa pela mudança de comportamento baseada no conhecimento (educação), pois sem o suporte do conhecimento, qualquer ação ou intervenção do ser humano no meio em que vive se torna frágil e ineficaz."

Ricklefs (2003) afirma que o aumento da população, seu desenvolvimento tecnológico e seu crescente materialismo aceleraram grandemente o processo de degradação ambiental terrestre e destaca que:

"Como conseqüência, a compreensão ecológica é agora necessária mais do que nunca para aprendermos as melhores políticas de manejar as bacias hidrográficas, as terras cultivadas, os alagados, e outras áreas, geralmente chamadas de sistemas de suporte ambiental, dos quais a humanidade depende para alimentação, suprimento de água, proteção contra catástrofes naturais e saúde pública."

O ensino da Ecologia pode e deve contribuir para o reforço das capacidades de formação do indivíduo enquanto cidadão lançando as bases de uma "Educação para a Cidadania". Segundo Caldeira (2005), ensinar ciências não se resume só a fatos, conceitos, princípios e leis, mas compreende uma dimensão de desenvolvimento de atitudes, habilidades e valores na formação do cidadão. Além disso a compreensão profunda do funcionamento dos sistemas ecológicos envolve a formação de valores estéticos, éticos e morais, que irão possivelmente determinar a conduta dos cidadãos em formação. E de maneira mais prática, os conceitos ecológicos são fundamentais na elaboração de políticas públicas, empreendimentos minimamente impactantes e da efetiva participação da sociedade no processo de gestão ambiental.

Segundo Lacreu (1998) o conhecimento dos fenômenos naturais, suas leis, etc., é o que nos permite decidir e atuar de forma a resolver as nossas necessidades sem destruir o nosso planeta. Para Seniciato (2006), se o aluno aprender sobre a dinâmica dos ecossistemas, ele estará mais apto a decidir sobre os problemas ambientais e sociais de sua realidade quando for solicitado. O que é extremamente bem vindo nos dias atuais, em que enfrentamos diversas conseqüências da ação transformadora da paisagem e das condições ambientais pelo ser humano. 
Podemos citar algumas dessas conseqüências: redução da produtividade pesqueira, chuva ácida, impermeabilização dos solos, assoreamento de rios, redução dos recursos hídricos, aquecimento global, alem de muitos outros (Mucci, 2005).

Todos esses elementos dificultam a sobrevivência da espécie humana, e de certa forma tornam-na menos prazerosa, reduzindo a qualidade de vida em todo o planeta. Hoje a contaminação de águas, do ar e de alimentos, e conseqüente degradação do meio ambiente, é a principal causa de moléstias que afligem a humanidade e pioram sua qualidade de vida. (Kupstas et al., 1997). Tais conseqüências advieram muitas vezes de uso inadequado dos recursos naturais, que em grande parte envolveram pouco ou nenhum estudo ecológico.

Com o desenvolvimento da técnica buscava-se conforto, saúde e alta qualidade de vida, ironicamente, essa luta desenfreada em busca de "uma vida melhor" foi justamente a causa da maior parte dos problemas, seja de saúde ou de conforto, que vivemos hoje (Kupstas et al., 1997)

Uma educação em cujos objetivos esteja incluída a formação de valores, é uma educação que se preocupa também em como os alunos irão aplicar os conhecimentos adquiridos (Seniciato, 2006).

A problemática ambiental que surge como um reflexo da modernidade, coloca a necessidade de criar uma consciência a respeito de suas causas e possibilidades de resolução, passando por um processo educativo, e a construção de novas formas de desenvolvimento.

Salientamos que neste processo educativo de formação de valores, para a construção de novas formas de desenvolvimento, devem estar incluídos os conceitos científicos ecológicos relacionados a problemática. Pois como foi comentado acima a ignorância traz uma visão distorcida da realidade, que pode levar a atitudes precipitadas.

Como professor de biologia, ensinando ecologia estaríamos contribuindo para a formação de seres humanos mais aptos, com hábitos de conduta condizentes com o almejado desenvolvimento sustentável, desenvolvendo a responsabilidade para com o meio ambiente, a capacidade de trabalho em equipe, a cooperação, a solidariedade, o desenvolvimento de uma visão ética e menos antropocêntrica do mundo, com o estímulo da valorização e do respeito pela diversidade biológica. E o mais importante, respeito adquirido através do conhecimento ecológico da natureza.

\section{Conclusão}


Concluímos que é fundamental realizar uma reflexão sobre nosso papel de educadores no processo de estabelecimento da sustentabilidade como princípio de nossa sociedade. A ecologia fornece subsídios conceituais para buscar a compreensão dos processos naturais, estes conceitos podem fundamentar as práticas sociais promovendo a aplicação do tão almejado conceito de desenvolvimento sustentável. Não excluímos o relevante papel desempenhado pelas outras disciplinas cientificas, (ciências biológicas, exatas e humanas), nesse processo, uma vez que a própria ecologia e o conceito de desenvolvimento sustentável são essencialmente interdisciplinares. E para a real aplicação e estabelecimento da sustentabilidade em nossa sociedade faz-se necessária a ruptura dos estanques conceituais entre as diversas disciplinas do conhecimento humano. Para a elaboração e desenvolvimento de novos conceitos, paradigmas e tecnologias que dêem conta de promover a satisfação das necessidades fisiológicas, econômicas, sociais, culturais e ecológicas através de uma utilização racional, consciente e sustentável dos recursos naturais de nosso planeta, de forma a não colocar em risco a qualidade de vida de todas as populações da biosfera.

É, portanto, necessária uma formação que capacite os atores, a participação na tomada de decisões e elaboração de leis e políticas públicas sustentáveis. Que conservem os processos ecológicos responsáveis pela produtividade dos ecossistemas (Ricklefs, 2003). Para exercer seu direito, coletivo e inalienável, as presentes e futuras gerações, a um ambiente saudável e ecologicamente equilibrado como assegurado na constituição de 1988 (Philippi e Malheiros, 2005) e participar de fato da administração ecológica de sua região. Afinal segundo Ricklefs (2003), os processos ecológicos contêm a chave para a política ambiental e o desenvolvimento sustentável.

Segundo Fumagalli (1998) o conhecimento cientifico pode possibilitar uma participação ativa e com senso critico numa sociedade como a atual, na qual o fato cientifico está na base de grande parte das opções pessoais que a prática social exige. O aprendizado de conceitos de Ecologia no Ensino Médio é extremamente importante para o efetivo exercício da cidadania.

Após nossa revisão acreditamos que a utilização das aulas de campo, entre outras metodologias didáticas, tem papel fundamental no processo de ensino aprendizagem de ecologia por seu aspecto estético motivador e por buscar reduzir a fragmentação do conhecimento (Seniciato, 2006) e por proporcionar a experiência colateral que tem como característica a riqueza de possibilidades no processo de geração de conceitos ecológicos, pois possibilita a percepção de uma série de fenômenos naturais próximos ao aluno durante o ensino aprendizagem de ecologia (Caldeira, 2005).

Ao proporcionarmos o contato direto com o objeto de estudo da ecologia, favorecemos um processo de aprendizagem que envolve os passos de, observação de fenômenos, elaboração 
de problemas científicos, elaboração de hipóteses explicativas. Diferentemente do que ocorre quando lidamos com representações acabadas (Caldeira, 2005).

Dessa forma ao aprender através da experiência colateral, orientado pelo professor, o aluno tem a oportunidade de considerar a totalidade dos diversos elementos envolvidos em certo fenômeno durante a elaboração de suas hipóteses frente às questões levantadas por ele ou por seu professor. É importante ressaltar que as hipóteses construídas nesse processo devem ser confrontadas com aquelas aceitas pela comunidade cientifica, e quando necessário, e possível, devem ser realizados os experimentos pertinentes a sua confirmação.

\section{Referências}

Assunção e Malheiros, In: Educação ambiental e sustentabilidade Philippi Jr., A. ; Pelicioni, M. C. F. (Org.) Coleção ambiental, São Paulo: Manole, 2005.

Begon, M., Harper, J.L. e Towsend, C.R. Fundamentos em ecologia. 2ª. ed. Porto Alegre: Artmed, 2006.

Caldeira, A.M.A. Semiótica e relação pensamento e linguagem no ensino de ciências naturais. 2005. 175f. Tese (Livre-Docência) - Faculdade de Ciências, Universidade Estadual Paulista. Bauru.

Coimbra, J. A. A., O outro lado do meio ambiente. São Paulo: Cetesb, 1985.

Curado, P.M. e Angelini, R. Avaliação de atividade de Educação Ambiental em trilha interpretativa, dois a três ano anos após sua realização Acta Sci. Biol. Sci. Maringá, v. 28, n. 4, p. 395-401,

Oct./Dec., 2006

Fink, D. R., Legislação ambiental aplicada, 733-759 In: Saneamento saúde e ambiente, Philippi Jr., A. (Ed.) Coleção ambiental, Barueri: Manole, 2005.

Fumagalli, L. O Ensino de Ciências Naturais no Nível Fundamental da Educação Formal: argumentos a seu favor. p. 27-51 In: Weissmann, H. (org.). Didática das Ciências Naturais: contribuições e reflexões. Porto Alegre: Artmed, 1998.

Heemann, A., Heemann, N. Natureza e percepção de valores. Desenvolvimento e meio ambiente, $n^{\circ}$ 7, p. 113-116, jan./jun. 2003. editora UFPR.

Hoernig, A. M. e Pereira, A. B. Aulas práticas no ensino de ciências: o que pensam os alunos.

Revista brasileira de pesquisa em educação em ciências, Porto Alegre, v. 4, n. 3, p. 53-76

set./dez. 2004. 
Kazmierczak, M.L. Desenvolvimento de um algoritmo para modelar a suscetibilidade de desertificação no nordeste do Brasil: Algoritmo ISD. Anais IX Simpósio Brasileiro de Sensoriamento Remoto, Santos, Brasil, p. 133-143. 11-18 setembro 1998, INPE.

Kupstas, M. (org.) Ecologia em debate. Coleção debate na escola. São Paulo: Moderna, 1997. Lacreu, L.I. Ecologia, Ecologismo e Abordagem Ecológica no Ensino das Ciências naturais: Variações sobre um Tema. p. 53-76. In: Weissmann, H. (org.) Didática das Ciências naturais: contribuições e reflexões. Porto Alegre: ArtMed, 1998.

Linhares, S., Gewandsznajder, F. Biologia hoje. São Paulo: Ática, 2005.

Lopes, G. C. L. R. e Allain, L. R. Lançando um olhar crítico sobre as saídas de campo em biologia através do relato de uma experiência. In: VIII Encontro Perspectivas do Ensino de Biologia, 6 , 2002, São Paulo. Anais... São Paulo: FEUSP, 2002.

Machado, A.B.M. Conservação da natureza e educação. In: Anais do Congresso Nacional Sobre essências Nativas, Campos do Jordão, São Paulo. p. 109-108, 1982.

Milaré, É. Direito do ambiente, 2a. ed. São Paulo: Editora Revista dos Tribunais, 2001.

Mucci, J. L. N. Introdução às ciências ambientais, 15-37 In. Educação ambiental e sutentabilidade Philippi Jr., A. e Pelicioni, M. C. F. (Ed..) Coleção ambiental, Barueri: Manole, 2005.

Nebel, B. J., Enviroment science. The way the world works. Englenwood Cliffs: Prentice Hall, 1990.

Odum, E.P. Ecologia. 4a ed. Rio de Janeiro: Guanabara-Koogan, 1988.

Philippi Jr., A. e Malheiros, T. F. Saúde ambiental e o desenvolvimento 59-83. In. Educação ambiental e sutentabilidade. Philippi Jr., A. e Pelicioni, M. C. F. (Org.) , Barueri: Manole. Coleção ambiental,2005.

Piaget, J. Seis estudos de psicologia. 24. ed. Rio de Janeiro: Forense Universitária. 2001.

Pinheiro da Silva, P.G. 0 ensino da botânica no nível fundamental: Um enfoque nos procedimentos metodológicos. 125f. 2007. Tese (Doutorado em Educação) - Faculdade de Ciências, Universidade Estadual Paulista. Bauru.

Pinto - Coelho, R.M. Fundamentos em ecologia. Porto Alegre: Artmed, 2000.

Queiroz, J, El - Hani, C.N. Definindo semiose como processo emergente. Cognitio-Estudos: Revista Eletrônica de Filosofia, p. 22 - 39. 2005.

Raven, P.H., Evert, R.F., Eichhorn, S.E. Biologia Vegetal. 5a ed. Rio de Janeiro: Guanabara Koogan, 2001. 
Ricklefs, R.E. A economia da natureza. 5ạ. ed. Rio de Janeiro: Guanabara Koogan, 2003.

Robim, M.J. e Tabanez, M.F. Subsídios para implantação da Trilha Interpretativa da Cachoeira Parque Estadual de Campos do Jordão. Rev. Instituto Flor, São Paulo, v. 5 n. 1, p. 65-89, 1993.

Santaella, L. O que é semiótica. São Paulo: Brasiliense, 1983.

Santos, S. A. M. A excursão como recurso didático no ensino de biologia e educação ambiental. In: Anais do VIII Encontro perspectivas do ensino de biologia, 6, 2002, São Paulo. São Paulo: FEUSP, 2002.

Seniciato, T. A formação de valores estéticos em relação ao ambiente natural nas Licenciaturas em Ciências Biológicas da UNESP. 197f. 2006. Tese (Doutorado em Educação) - Faculdade de Ciências, Universidade Estadual Paulista. Bauru.

Silva, J. A., Direito ambiental constitucional. 3ạ. ed. São Paulo: Malheiros, 2000.

Souza, G. M. e Buckeridge, M.S. Sistemas complexos: novas formas de ver a Botânica. Revista Brasil. Bot., V.27, n.3, p.407-419, jul.-set. 2004

Gustavo da Fonseca - mestrando do Programa de Pós Graduação em Educação para o Ensino de Ciências da Faculdade de Ciências da UNESP, Bauru, SP. Professor na Escola Estadual de Ensino Médio Profa. Judith Sant'Anna Diegues, Ilha Comprida, SP, e no Colégio Técnico Eng. Agr. Narciso de Medeiros, Iguape, SP. fonseca_bio@yahoo.com.br

Ana Maria de Andrade Caldeira - Livre Docente do Programa de Pós Graduação em Educação para o Ensino de Ciências da Faculdade de Ciências da UNESP, Bauru, SP. caldeira@netsite.com.br 